\title{
Especial
}

\section{A AÇÃO DO LÍRICO NA DRAMATURGIA CONTEMPORÂNEA}

THE LYRICAL ACTION IN CONTEMPORARY DRAMA

\section{LA ACCIÓN LÍRICA EN LA DRAMATURGIA CONTEMPORÁNEA}

\section{Cleise Furtado Mendes}

\section{Cleise Furtado Mendes \\ Professora da Escola de Teatro e do Programa de Pós-Graduação em Artes Cênicas da UFBA, pesquisadora do CNPQ, dramaturga e ensaísta}




\section{Resumo}

O artigo reavalia pressupostos de algumas teorias baseadas na "crise do drama" que se orientam, exclusivamente, pela presença de recursos épicos na dramaturgia moderna e contemporânea, propondo o exame das estratégias líricas recorrentes em novas formas de escrita dramatúrgica. Com exemplos da dramaturgia brasileira, o estudo sugere uma abordagem crítico-teórica que reconheça o papel estruturante dos procedimentos líricos para a reconfiguração da forma dramática e para a pluralidade discursiva que marca a produção atual.

Palavras-chave: Drama lírico, Dramaturgia contemporânea, Teorias do drama.

\section{Abstract}

This article discusses the principles of some theories based on "drama crisis" that are guided solely by the presence of epic features in modern and contemporary drama, proposing the observation of recurring lyrical strategies in new forms of playwriting. With examples of Brazilian drama, the study suggests a critical-theoretical approach that recognizes the crucial role of lyrical procedures for the reconfiguration of the drama and the discursive plurality that marks the current production.

Keywords: Lyrical drama, Contemporary drama, Drama theories.

\section{Resumen}

Este artículo cuestiona los principios de algunas teorías basadas en la "crisis del drama" que se guían únicamente por la presencia de características épicas en el drama moderno y contemporáneo, proponiendo la observación de los rasgos líricos recurrentes en nuevas formas de escritura dramatúrgica. Tomando ejemplos de la dramaturgia brasileña, este estudio sugiere un enfoque crítico-teórico que reconoce el papel fundamental de los procedimientos líricos para la reconfiguración del drama y para la pluralidad discursiva que marca la producción actual. Palabras clave: Drama lírico, Dramaturgia contemporánea, Teorías del drama.

A observação dos temas e procedimentos líricos que emergem na escrita de peças teatrais desde o alvorecer do século XX revela características 
de composição recorrentes nas diversas possibilidades de desconstrução e reconfiguração da forma dramática, várias delas ainda em curso na atual produção dramatúrgica. As transformações ocorridas no drama a partir da experiência pioneira de Strindberg em suas peças oníricas (Rumo a Damasco, $O$ sonho, A grande estrada) e de alguns desdobramentos no Stationendrama expressionista (Ernst Toller, Georg Kaiser), no teatro-pânico de Arrabal (Fando e Lis, Oração, Guernica), nos rituais cênicos de Jean Genet (O balcão, As criadas, Os negros) ou na radical condensação de meios em Samuel Beckett (sobretudo nos últimos "dramatículos") colocam-nos diante de uma forma híbrida, claramente estruturada pelas estratégias da lírica, ainda que em muitos casos articuladas a recursos épicos.

No entanto, apenas a vertente épica foi devidamente identificada e valorizada pelos autores que se debruçaram sobre a multifacetada produção dramatúrgica que emerge nas primeiras décadas do século XX e que, deslocando os paradigmas aristotélico e hegeliano, subverte categorias clássicas do gênero, rumo a uma revitalização e reinvenção da forma dramática que ainda não cessou de manifestar seus efeitos. A referência crucial para esse reconhecimento exclusivo das tendências épicas na dramaturgia moderna encontra-se na obra já clássica de Peter Szondi, Teoria do drama moderno [1880-1950], cuja primeira edição, pela Suhrkamp Verlag, é de 1956, portanto anterior à imensa variedade de textos para a cena surgidos nos últimos cinquenta anos.

A tese de Szondi, amplamente conhecida, é a de que uma "crise do drama" teria se instalado a partir de fins do século XIX, graças a uma crescente contradição interna entre a forma dramática e os novos conteúdos que esta buscaria assimilar, naquele momento histórico. Para o autor, o que constituiria o drama propriamente dito seria apenas "uma determinada forma de poesia teatral" que teria surgido no Renascimento, com desenvolvimento na Inglaterra elisabetana e na França do século XVII e sobrevivência no classicismo alemão. Szondi não oferece exemplos concretos desse drama "absoluto" salvo a menção, em poucas linhas, de personagens de Corneille e Hebbel -, e sim a descrição teórica de seus traços essenciais: caráter primário da relação dramática, que desconecta o mundo encenado de tudo que lhe é externo e obriga-o a "representar-se a si mesmo", por meio de uma ação sempre 
presente, de modo que "o decurso temporal do drama é uma sequência de presentes absolutos."; ausência total do autor, que "fala" apenas através das personagens, daí o domínio absoluto do diálogo, da comunicação intersubjetiva; exigência da unidade de tempo e lugar, bem como da causalidade na ligação entre as cenas, pois qualquer deslocamento espacial ou cronológico denunciaria a presença de um "eu-épico" (SZONDI, 2001, p. 32-33).

Essa cerrada dialética intersubjetiva, segundo Szondi, começaria a entrar em crise nas obras de dramaturgos como Ibsen, Tchekhov, Strindberg, Maeterlink e Hauptmann (os cinco autores examinados por ele no primeiro capítulo, justamente intitulado "A crise do drama"), com o crescente colapso dos traços constitutivos da ação, da fábula, das personagens e, sobretudo, do diálogo. A superação dessa crise, ainda de acordo com o teórico alemão, dar-se-ia por um progressivo afastamento do dramático em direção à forma épica do teatro.

A partir daí teria origem a "dramaturgia épica moderna", no ponto "em que a peça social burguesa, que outrora adotara o princípio formal do drama clássico, converte-se necessariamente em épica a partir da contradição de forma e conteúdo desenvolvida no curso do século XIX" (SZONDI, 2001, p. 68). O curioso é que esta afirmação é feita durante uma análise de Sonata dos espectros, de Strindberg - um autor de capital importância na introdução de recursos líricos na dramaturgia moderna -, e apesar disso o teórico concentra-se exclusivamente na detecção e exaltação do épico. Szondi lamenta que, com o suicídio da personagem Hummel ao final do segundo ato, Strindberg tenha "privado" o terceiro ato da peça da condução desse "sujeito épico", daí resultando que o final da peça "tinha de fracassar porque ele deveria novamente engendrar o diálogo sem o apoio do épico" (SZONDI, 2001, p. 69).

Jean-Pierre Sarrazac (2012), criticando a leitura de Szondi, lembra que "o sujeito da dramaturgia subjetiva de Strindberg não é apenas épico", visto que seria "alternadamente, ou mesmo simultaneamente, épico e dramático" (p. 27). Mais adiante, defende o terceiro ato de Sonata dos espectros como um "fim de peça em forma de abertura caracteristicamente lírica." Em seguida, menciona, de passagem, a questão que tem relevância para o enfoque que ora proponho: "Aqui, Szondi não parece avaliar a importância do lírico, ao lado do dramático e do épico, nas estruturas dramatúrgicas modernas" (SARRAZAC, 2012, p. 28). 
No entanto, em que pese a preciosa contribuição de seu trabalho crítico-teórico ao campo atual dos estudos de dramaturgia, o próprio Sarrazac não vem conferindo a devida atenção às estratégias líricas na análise de peças modernas e contemporâneas. Na lúcida crítica a que submete o livro de Szondi, Sarrazac opõe-se à visão teleológica do teórico alemão, que implicaria uma ideia de "progresso" da dramaturgia em direção ao épico (o Novo), como um fim a atingir na "melhoria" evolutiva do gênero, como se a "crise" do dramático (o Antigo) tivesse de ser assim "superada" (SARRAZAC, 2012, p. 24). Mas quando apresenta sua noção de rapsódia para compreender as obras híbridas da escrita dramática contemporânea, esta surge "ligada, de saída, ao domínio épico" (SARRAZAC, 2012, p. 152), omitindo uma vez mais a presença e a força do lírico nessas criações.

Não se pretende, aqui, substituir o épico pelo lírico no horizonte do drama, repetindo formulações de caráter teleológico, como se a crescente liricização que se constata nos textos atuais sinalizasse algum tipo de "pós-modernidade" ou "pós-dramaticidade" no âmbito da dramaturgia ou apontasse uma superação da forma dramática. Sem desconhecer a importância dos recursos épicos (aliás, desde as tragédias gregas), busca-se uma ampliação das referências críticas e teóricas para obter visão mais abrangente da multiplicidade da atual produção dramatúrgica. Para isso, há que deslocar certos hábitos na análise de peças teatrais, como o de apenas reconhecer a presença do lírico na linguagem das réplicas, na tessitura do diálogo. Isso implica dizer que o aspecto a ser aqui enfatizado é o papel do lírico como tendência estruturante das várias instâncias da composição dramatúrgica, no desenho das situações, no singular modo de ação das personagens imersas num processo de subjetivação.

Os traços geralmente apontados como características de uma escrita atual na dramaturgia sugerem conexões com alguns procedimentos que certos teóricos há tempos apontam como próprios do gênero lírico. Aí podem ser incluídos: o predomínio da função poética sobre a representativa na linguagem; união de som e sentido, com ênfase na música das palavras; fusão de sujeito e objeto da percepção; subjetivação de espaço e tempo; presença da repetição como recurso de fazer perdurar o fluxo lírico, com uso de estribilhos e variações temáticas; recusa da lógica sintática, com predileção por constru- 
ções paratáticas (com partes coordenadas, livres de hierarquia), entre outros. De fato, é possível afirmar que essas feições de há muito vêm sendo identificadas na escrita de textos para a cena e que elas remetem, em muitas formas e aspectos, a um modo de configuração poética característica do lírico. Porém, a supervalorização do épico como "progresso" e mesmo "superação" da forma dramática, como foi dito, não deixou espaço para que a contribuição de outros gêneros e tipos de discursos fossem reconhecidos no processo geral de renovação da dramaturgia. Disso resulta, por certo, a parca produção bibliográfica sobre a presença do lírico no drama contemporâneo, mesmo no âmbito dos estudos acadêmicos.

Seja na instância da intriga, dos caracteres ou nas formas de enunciação, os traços constitutivos do drama rigoroso ou absoluto mostram-se como que dissolvidos em textos que articulam características lírico-dramáticas (sem esquecer a contribuição de outros gêneros discursivos). Tais marcas de uma evidente liricização, associadas a processos de subjetivação nos temas, estão presentes em obras de autores tão diversos - tanto no teor de sua escrita quanto nas inserções culturais - quanto Thomas Bernhard, Bernard-Marie Koltès, Marguerite Duras, Wajdi Mouawad, Sarah Kane, Matéi Visniec, Jon Fosse, Enrique Buenaventura, Juan Mayorga, para citar apenas alguns já amplamente reconhecidos pela crítica especializada.

No Brasil, as possibilidades de miscigenação lírico-dramática - com distintas consequências para a diversidade dos textos levados à cena - integram as estratégias de dramaturgos que emergiram, sobretudo, nas duas últimas décadas, como Cláudia Barral, Fernando Bonassi, Ana Maria Franco, Adelice Souza, Paulo Henrique Alcântara, Antônia Pereira, Dionísio Neto, Bosco Brasil, João Falcão, Marcos Barbosa, Cláudio Simões, João Sanches, Gil Vicente Tavares, Leonardo Moreira, Rodrigo de Roure, Roberto Alvim, Fábio Mendes, entre muitos outros. São elementos comuns a boa parte dessa produção o predomínio da função poética sobre a referencialidade; a fragmentação do diálogo cotidiano em emissões que parecem surgir aleatoriamente, aos poucos permitindo a eclosão de sentidos e terminando por alcançar um efeito curioso a partir de réplicas esparsas, silêncios ou vozes paralelas; a permanência das situações como que suspensas no tempo e no espaço, sem progressão dramática; o processo de subjetivação que isola as personagens, dissolve o clássico 
conflito e transforma suas enunciações em feixes de monólogos ou fluxos de reminiscências, fazendo que a linguagem adquira inequívoca força lírica.

Contudo, esse não é procedimento recente em nossa produção dramatúrgica, visto que estratégias líricas são a base estrutural já em textos de autores consagrados como Doroteia, ou Senhora dos Afogados, de Nelson Rodrigues, Rastro atrás, de Jorge Andrade, ou as peças-poemas de Hilda Hilst. Embora mantenham traços estruturais do drama, como rubricas de cenário e réplicas atribuídas a distintos personagens, tais peças funcionam como poemas dialogados, com dominância do ritmo e da repetição lírica, numa polifonia de fontes enunciativas, como em $O$ rato no muro, de Hilst. Esse tipo de construção textual e cênica já se aproxima, em grandes linhas, da ideia aqui proposta de um drama lírico.

Essa noção necessita de esclarecimento, visto que a expressão vem comportando vários significados na história do teatro, além de interfaces com a história da música. De modo geral, costuma designar dramas com acompanhamento musical, ou teatro cantado, no qual se intercalam cenas com música e cenas dialogadas, e isso por vezes chega a contemplar desde textos antigos que incluem cantos corais, até O Livro de Cristóvão Colombo, de Claudel. Na tradição espanhola, drama lírico refere-se ao "gênero chico", uma espécie de subgênero da zarzuela, ou opereta. Na França, a expressão drame lyrique surge no século XIX para distinguir óperas de tema "sério", com conteúdo dramático, que se afastam do modelo da grande ópera. Por outro lado, Emil Staiger, alertando para o fato de que em nenhuma obra concreta estão ausentes traços dos três gêneros, faz a seguinte ilustração: "Usamos, por exemplo, a expressão 'drama lírico'. 'Drama' significa aqui uma composição para o palco e 'lírico' refere-se ao tom, que se mostra mais importante na determinação da essência que na 'exterioridade da forma dramática" (STAIGER, 1997, p. 14).

Diante dessa flutuação conceitual, cumpre esclarecer que minha proposição de um drama lírico tem sentido totalmente distinto dos exemplos anteriores, tanto os da tradição cênico-musical, quanto o de Staiger, pois leva em conta precisamente as modificações introduzidas na "exterioridade da forma dramática”, quando impregnada pelo lírico. Não me refiro, portanto, apenas ao tom, ao estilo da linguagem, nem mesmo ao "clima lírico" (lyrische Stimmung) 
presente em certas obras prioritariamente dramáticas. Com a expressão "drama lírico" busco conceituar certos tipos de composição em que se acham não apenas mesclados procedimentos formais desses gêneros, mas aos quais o lírico fornece traços estruturantes que logram reconfigurar, por vezes de modo radical, as convenções dramáticas.

Em estudo introdutório, publicado há mais de três décadas, busquei traçar um modelo dessa forma de drama (MENDES, 1981). Nesse escrito, comparo as diferentes estratégias do lírico e do dramático ao lidar com as categorias de tempo, espaço e ação, com o objetivo de descrever um tipo de composição na qual se articulam traços formais dos dois gêneros e produz uma forma peculiar de escrita dramatúrgica. O modelo teórico de drama lírico que então propus elegia como ponto de partida a peça Esperando Godot, de Beckett, pela transparência com que esse texto expõe uma estrutura de ritmo recorrente, alicerçada na circularidade da ação e na subjetivação do espaço (projetado como "palco interior") e do tempo (dilatado em espiral interminável). Mas já então observava, ao final do artigo, que seria possível "inscrever nesse modelo grande parte da dramaturgia expressionista e das chamadas peças de absurdo" (MENDES, 1981, p. 66).

Hoje, a observação dos textos dramatúrgicos surgidos nos trinta e pouco anos desde a publicação desse estudo exige a ampliação de seus limites, para contemplar modalidades de escrita cuja liberdade ultrapassa as inovações surgidas na segunda metade do século XX. Na diversidade dessa produção, é possível observar como traço comum o efeito dos procedimentos líricos nas transformações ocorridas e ainda em curso na reconfiguração da forma dramática, mediante experimentos híbridos, abertos a diferentes modos de estruturação narrativa e gêneros de discurso, num transbordamento polifônico que ainda não cessou de causar surpresas aos leitores/espectadores.

A observação de fenômenos típicos da linguagem lírica - como a fusão de som e sentido, padrões rítmicos de recorrências sonoras, fragmentação da sintaxe e outros - apresenta-se hoje como uma ótica das mais produtivas para leitura e interpretação dos textos para teatro, quando se considera que o diálogo ficcional faz bem mais do que apenas reproduzir ocorrências da fala cotidiana. Ao criar sua própria "língua", o teatro é capaz de magnificar toda a complexidade já existente nos usos da linguagem. Contudo, a 
ação do lírico abrange textos em que essas estratégias atingem não só o diálogo, incidindo simultaneamente na subjetivação de espaço e tempo, na circularidade das situações, na composição (ou decomposição) da fábula, disseminada ao nível molecular, na identidade móvel ou indeterminada das personagens, no esvaecimento do conflito. A própria ideia de ação merece ser revisada nesse contexto, para compreender também a errância do eu lírico no palco subjetivo.

A questão do silêncio sobre o lírico e seu papel no contexto geral de renovação da dramaturgia moderna tem implicações não só estéticas, mas também ideológicas. Nesse sentido, são providenciais as críticas apresentadas por Jean-Pierre Sarrazac à tese de Szondi (de 1954) sobre o épico como "superação" de um drama em crise. Para Sarrazac, o livro de Szondi, por estar "profundamente enraizado" numa tradição crítica hegeliano-marxista que inclui Walter Benjamin, Georg Lukács e Theodor Adorno, não conseguiria "livrar-se completamente dos preconceitos de decadência e formalismo" que marcam boa parte dessa linhagem de crítica sociológica (SARRAZAC, 2012, p. 22).

A clássica formulação hegeliana de que o drama reúne a objetividade da epopeia e a subjetividade da lírica esteve no horizonte de muitas tentativas de compreender a proliferação de formas desviantes do modelo canônico do gênero, a partir do drama moderno. No curso desses esforços teóricos, a inclinação ao épico foi vista como possibilidade de a dramaturgia abrir o seu foco para o tratamento mais amplo de temas sociais, reforçando a objetividade das referências de tempo e espaço e recusando o fechamento das relações intersubjetivas ${ }^{1}$. Por outro lado, a tendência ao lírico, no drama, permaneceu vinculada à vida interior das personagens, à estase da ação, a solilóquios em que a linguagem está vocacionada à expressão de temas "intimistas" e como tais mais afeitos à problemática do indivíduo isolado do que às grandes questões político-sociais.

Diante dessa forçada dicotomia, que alimentou teorias voltadas ao exclusivo reconhecimento de um devir épico como garantia da saúde do dra-

1. Iná Camargo Costa, discutindo a resistência da crítica brasileira ao teatro épico, inicia sua exposição de modo incisivo: "Numa fórmula extremamente sumária, podemos dizer que o teatro épico, do qual Brecht é o mais importante emblema, foi uma espécie de arma forjada entre o final do século passado e as três primeiras décadas deste por artistas adeptos da causa da revolução proletária, no âmbito da luta cultural" (1998, p. 75). 
ma, convém fazer a releitura de certos textos capitais. Em artigo de 1958, intitulado "Discurso sobre lírica e sociedade", Theodor Adorno apresenta uma interpretação social da lírica que cria notável deslocamento nas concepções tradicionais do gênero. Depois de afirmar que "a grandeza das obras de arte consiste unicamente em revelar o que a ideologia oculta", Adorno enfrenta o ceticismo de seus ouvintes ("Vocês concebem a lírica como algo contraposto à sociedade, como algo plenamente individual") para afirmar uma "essência social da lírica" fundada na resistência do sujeito poético à falsa consciência:

\begin{abstract}
Mas esta exigência que se faz à lírica, a exigência de que seja palavra virginal, é em si mesma uma exigência social. Ela implica o protesto contra uma situação social que cada indivíduo experimenta como hostil, estranha, fria, opressiva, situação que se imprime negativamente na formação lírica: quanto mais pesada for a situação, tanto mais inflexivelmente lhe resiste a formação, negando-se a inclinar-se ante qualquer coisa heterônima e constituindo-se exclusivamente segundo suas próprias leis. [...] A idiossincrasia do espírito lírico contra a prepotência das coisas é uma forma de reação à coisificação do mundo, ao domínio das mercadorias sobre os homens, domínio que se estende desde o começo da idade moderna, e que, desde a revolução industrial, tornou-se a força dominante da vida. (ADORNO apud COSTA LIMA, 1975, p. 345.)
\end{abstract}

Escritas quase meio século antes de certos textos dramatúrgicos não só influenciados, mas realmente estruturados por estratégias líricas, as palavras de Adorno encontram admirável convergência com alguns desdobramentos atuais da poética do drama. Em seu último livro, Sarrazac revisita a ideia de "teatro íntimo", partindo das quatro peças de câmara de Strindberg e do programa de abertura do Intima Teater, fundado pelo dramaturgo sueco em Estocolmo, em 1907. Esse teatro íntimo, em que o eu e o mundo são colocados em tensão, "situa-se nos antípodas de qualquer teatro intimista", alerta Sarrazac, pois este "significa fechamento, enclausuramento, restrição da ação dramática à esfera ou à barreira fantasmática da 'vida privada', enquanto que, no teatro íntimo, o interior, o espaço do dentro, manifesta uma aspiração social e cósmica ao exterior." (2013, p.22). Trata-se, aí, de conceber que a passagem de uma dramaturgia da intersubjetividade para uma dramaturgia da intrassubjetividade não significa o fechamento sobre os segredos de uma individualida- 
de e o isolamento da temática social, mas antes o abrir-se da intimidade das personagens para o espetáculo do mundo.

A ação do lírico tem o poder de redesenhar as formas canônicas da tessitura dramática e de engendrar modos peculiares de composição dramatúrgica. A pluralidade discursiva que marca a produção atual contempla, na variedade das escritas, estratégias próprias do gênero lírico que, nos planos formal e temático, desempenham papel fundamental para a configuração de processos de subjetivação que subvertem as categorias tradicionais do drama e podem ser inscritos na noção de drama lírico aqui proposta. O teatro atual, apagando fronteiras e colocando em tensão vários gêneros discursivos, abrindo-se ao convívio com a heterogeneidade das práticas cênicas, torna-se um campo fértil para ocorrências de fenômenos complexos de enunciação. Nesse quadro, a percepção de traços líricos estruturantes na dramaturgia contemporânea pode contribuir para ampliar a análise da atual produção com um repertório de temas e técnicas que tem estado ausente das abordagens críticas mais recentes.

\section{Referências bibliográficas}

ADORNO, T. W. Discurso sobre lírica e sociedade. In: COSTA LIMA, L. Teoria da literatura em suas fontes. Rio de Janeiro: Francisco Alves, 1975. p. 343-354.

COSTA, I. C. Sinta o drama. Petrópolis: Vozes, 1998.

HILST, H. Teatro completo. São Paulo: Globo, 2008.

MENDES, C. F. O drama lírico. ART Music Review, Salvador, v. 2, n. 2, p. 47-67, jul./ set. 1981.

SARRAZAC, J.-P. (org.). Léxico do drama moderno e contemporâneo. São Paulo: Cosac Naify, 2012.

Sobre a fábula e o desvio. Rio de Janeiro: 7 Letras/Teatro do Pequeno Gesto, 2013.

STAIGER, E. Conceitos fundamentais de poética. Rio de Janeiro: Tempo Brasileiro, 1997.

SZONDI, P. Teoria do drama moderno (1880-1950). São Paulo: Cosac Naify, 2001.

Recebido em 16/08/2015

Aprovado em 21/08/2015

Publicado em 21/12/2015 